\title{
A study on the algebraic working processes of senior high school students in Ghana
}

\author{
Jones Apawu ${ }^{1}$, Nana Akosua Owusu-Ansah" ${ }^{2 *}$ and Peter Akayuure ${ }^{1}$ \\ ${ }^{1}$ Mathematics Education, University of Education, Winneba, Ghana \\ 2 Mathematics Education, University of Education, Winneba, Ghana \\ For correspondence: naowusu-ansah@uew.edu.gh
}

\begin{abstract}
The aim of this study was to examine the working processes employed by Ghanaian senior high school students when dealing with tiling pool problem algebraically. The study employed survey design, with a total sample of 304 Senior High School Form 1 students from three Senior High Schools in the Central Region of Ghana. Data were collected through Super Item test based on Structure of the Observed Learning Outcome (SOLO) taxonomy. Qualitative data were coded and analysed into themes. The results showed that most of the students surveyed were unfamiliar with the tiling pool problem and could not find a link between the algebraic concepts learnt and non-routine problems. It is recommended that high school teachers should consider students' working processes as integral part of their instructions and assessments.
\end{abstract}

Keywords: Algebraic thinking, SOLO taxonomy, Super Item Test, Working Processes.

\section{Introduction}

Over the years, a lot of attention has been paid to the teaching and learning of mathematics in Ghana (Mereku \& Cofie, 2008). However, assessment of the mathematics learned in Ghanaian classrooms for application leave much to be desired. As a result, students' algebraic thinking processes, which is key to their life long application of mathematics for decisions making, has received less or no attention at all in Ghana.

Algebraic thinking is very important in the development of students' mathematical knowledge. Many researchers (Fletcher, 2008; Kaput, 2008; Kriegler, 2008; Windsor, 2010) agree that algebraic thinking is an essential mathematical tool not only for school, but for life and it is therefore the way to go. Fletcher (2008) stated that Algebraic thinking is an integral part of mathematics and operating at higher level of algebraic thinking is an indication that an individual is equipped with high reasoning ability to engage in life. It is therefore a step in the right direction that, one of the major goals of mathematics education in Ghana is to improve higher order thinking skills (Ministry of Education (MOE), 2010). The researchers are of the view that to improve higher order thinking skills, emphasis should be placed on the teaching, learning as well as assessment of mathematics. After assessment, it is important for teachers to analyse students output for informed decisions about the students.

The Structure of the Observed Learning Outcome (SOLO) taxonomy is one of the theoretical frameworks that have been used extensively to analyse algebraic thinking levels of students in countries such as Malaysia, Pakistan and South Denmark. These countries have used test items referred to as Super Item test based on SOLO taxonomy as an alternative assessment tool for monitoring the growth of their students' cognitive ability. Super item test are test items based on the levels SOLO taxonomy that is the items are arranged to correspond with the five levels of the 
taxonomy (Collis, Romberg, \& Jurdak, 1986; Lam \& Fong, 1998; Lim \& Idris, 2006; Lim, Wun \& Idris 2005a; UNICEF, 2007; Wilson \& Iventosh, 1988). A super Item test is an item which can be placed in the five levels of the Solo Taxonomy. A learner, at the first level which is described as the Prestructural level, is categorized as not been able to understand the algebraic perspective of the given mathematical problem (super Item test). The learner at the uni-structural level can use one or a few relevant information given in the mathematical problem such as diagram or concrete object to provide a correct response to an aspect of the problem. At the multi-structural level, the leaner can select relevant point of the problem that aid in identifying pattern from one term in a sequence to the next term but will not be able integrate them. At the relational level, the learner can create a relationship in the pattern, generalise and represent such relationship mathematically. The Extended Abstract is the final level of SOLO taxonomy where a learner at this level, can generalise the relationships into a new and more abstract situation.

In Ghana, research studies on the use of SOLO taxonomy to assess and monitor students' cognitive growth is scarce. It is self-evident that, most teachers in Ghana base their judgement of students' cognitive growths on the total marks they obtained without paying attention to the quality of their mathematical working processes. Perusing the literature, there is no straight jacketed definition for mathematical working processes. In this study, mathematical working processes refers to the techniques employed in arriving at an answer when given a mathematical task. This study sought to determine the various working processes of first year senior high school (SHS) students on algebraic thinking problems. In an earlier publication, Owusu-Ansah, Asiedu-Addo and Cofie (2015) classified the algebraic thinking levels of Ghanaian JHS students using the levels they obtained in answering the test items.

The theoretical framework used is this study is SOLO taxonomy. In literature, SOLO taxonomy categorizes mental activity by quantity and quality attributes (Biggs \& Collis, 1982 cited in Lim \& Idris, 2006). SOLO taxonomy was chosen for this study after comparison with Piaget's Stages of Cognitive development and Van Hiele's Geometric thinking levels. SOLO taxonomy's generality as compared to Piaget's Stages of Cognitive development and Van Hiele's Geometrical thinking model made it the best framework for this study.

Mereku (2004) is of the view that the students' mathematical working processes are as important as the outcomes of such working process and their applicability. As researchers, we also think that analysing students' working processes is one of the ways to know how students are thinking. If a teacher can analyse his/her student's working processes, it would inform him/her as to how best the student's learning problems can be addressed. The purpose of this study was to examine the senior high school students' working processes in a non-routine algebraic problem.

\section{Methodology}

The study used survey as a strategy of enquiry to find out some working processes (Creswell, 2009) of first year SHS students. Both qualitative (structured interview) and quantitative data were collected. In this paper, the researchers concentrated on the qualitative aspects of the data gathered. The structured interview asked students how they came about their answers.

\section{Participants}

Purposive sampling was used to select three government SHSs. Two first year intact classes were randomly selected in three SHSs to participate in the study. First years were targeted to understanding their entry thinking processes as they transit from the junior high to senior high as well as to diagnose their predisposition to work with algebra demands at the senior high school. The Computer placement system in use in Ghana also places students from different parts of the country 
into the schools selected in this study. This made our sample more heterogeneous and characteristic of Ghanaian educational system. A total of 304 students (161 males and 143 females) with their age ranging from 14 to 17 responded to the tiling pool problem based on the SOLO taxonomy.

The Super Item Test

A super item, involving the use of square tiles around the floor of a pool, was labelled as an open mathematical problem to elicit students working processes. In line with literature, the tiling pool problem can be referred to as Super Item Test since the items were defined to follow the five levels of SOLO taxonomy (Lim, Wun \& Idris 2005a; UNICEF, 2007). The tiling pool problem test items were based on the JHS mathematics curriculum of Ghana and were comparable to those test items described as super item test and used by these researchers (Lim \& Idris, 2006; Lim, Wun, \& Idris, 2005a; Lim, Wun, Idris, \& Meng, 2005b). In this study, our super item test was an investigatory task of Mr. Mensah that required students to find the number of tiles required to tile around a given square swimming pool. Below is the task given to the participants

Mr. Mensah wants to design square swimming pools. He places tiles $\{\boldsymbol{\square}\}$ around the pool as shown below;

Pool 1

Pool 2

Pool 3
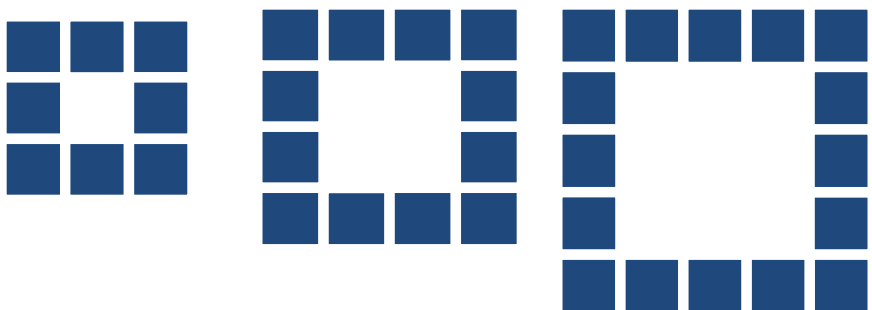

Use the information above to solve the following questions

a. How did you get the number of tiles required for pool 2?

b. How did you get the number of tiles required for pools 5, 9 and 12?

c. How did you get your relation for the number of tiles required to a pool of "X"?

d. If $\boldsymbol{x}$ represents the pool number and $\boldsymbol{y}$ represents the number of tiles. How did you get a relation to represent the number of the pool and the number of tiles?

e. How did you find the pool number that requires 128 tiles?

f. Mr Mensah decides to design hexagonal swimming pool with tiles around it, he realised the 1st, 2nd and 3rd pools required 8, 10 and 12 tiles respectively. How did you find the relation to represent the number of tiles for a hexagonal pool of any number?

\section{Data Collection Process}

The data collection took place early mornings prior to the usual class lessons in each school selected. Since the focus of the study was to collect qualitative data regarding students' working processes, two data collection processes were used. Thus, first, participants spent 45 minutes working on the super item. Second, a structured interview corresponding to each question was attached to the super item in which students stated how they arrived at their answers. The test items were piloted in a JHS and the result showed no ambiguity in responding to the item or interview guide. It was also possible to categorize the item in line with the SOLO taxonomy. 


\section{Data Analysis}

Codes were assigned to the various techniques employed by students to solve the test items. According to Kvale and Brinkman (2009), meaning coding involves attaching one or more keywords to a text segment to later permit identification. Thus, the codes were categorised in themes and their frequencies are reported in this study.

\section{Results}

Table 1. Students' Working Processes on the Uni-Structural Level.

\begin{tabular}{|c|c|c|c|}
\hline Item & Working Processes & $n$ & $\%$ \\
\hline \multirow{5}{*}{ 1(a) } & 1. Counted the tiles & 168 & 55.3 \\
\hline & 2. Failed to Attempt & 26 & 8.6 \\
\hline & 3. Found the Area of the Pool & 43 & 14.1 \\
\hline & $\begin{array}{l}\text { 4. Added } 4 \text { to the pool number/ Multiplied the } \\
\text { pool number by } 4\end{array}$ & 20 & 6.5 \\
\hline & 5. Others & 47 & 15.5 \\
\hline
\end{tabular}

Table 2. Students' Working Processes on the Multi-Structural Level.

\begin{tabular}{|c|c|c|c|}
\hline Item & Working Processes & $n$ & $\%$ \\
\hline \multirow{5}{*}{1 (b) i } & $\begin{array}{l}\text { 1. Used the multiples of 4/ } \\
\text { Relations and Mapping }\end{array}$ & 96 & 31.6 \\
\hline & 2. Failed to attempt & 59 & 19.4 \\
\hline & 3. Found the Area of the Pool & 30 & 9.8 \\
\hline & $\begin{array}{l}\text { 4. Added } 4 \text { to the pool } \\
\text { number/Multiplied the pool } \\
\text { number by } 4\end{array}$ & 40 & 13.2 \\
\hline & 5. Others & 79 & 26.0 \\
\hline \multirow{5}{*}{$1(\mathrm{~b}) \mathrm{ii}$} & $\begin{array}{l}\text { 1. Used the multiples of 4/ } \\
\text { Relations and Mapping }\end{array}$ & 83 & 27.3 \\
\hline & 2. Failed to Attempt & 71 & 23.4 \\
\hline & 3. Found the Area of the Pool & 25 & 8.2 \\
\hline & $\begin{array}{l}\text { 4. Added } 4 \text { to the pool number/ } \\
\text { Multiplied the pool number by } 4\end{array}$ & 39 & 12.8 \\
\hline & 5. Others & 86 & 28.3 \\
\hline \multirow{5}{*}{1 (b) iii } & $\begin{array}{l}\text { 1. Used the multiples of 4/ } \\
\text { Relations and Mapping }\end{array}$ & 82 & 27.0 \\
\hline & 2. Failed to Attempt & 74 & 24.3 \\
\hline & 3. Found the Area of the Pool & 21 & 6.9 \\
\hline & $\begin{array}{l}\text { 4. Added } 4 \text { to the pool number/ } \\
\text { Multiplied the pool number by } 4\end{array}$ & 38 & 12.5 \\
\hline & 5. Others & 89 & 29.3 \\
\hline
\end{tabular}


Table 3. Students' Working Processes on the Relational Level.

\begin{tabular}{|c|c|c|c|}
\hline Item & Working Processes & $n$ & $\%$ \\
\hline \multirow{5}{*}{$1(\mathrm{c})$} & 1. Obtained $4 x+4$ & 25 & 8.2 \\
\hline & 2. Failed to Attempt & 101 & 33.2 \\
\hline & 3. obtained $x^{2}$ & 12 & 3.9 \\
\hline & 4. Obtained $x+4$ or $4 x$ & 68 & 22.4 \\
\hline & 5. Others & 98 & 32.3 \\
\hline \multirow{5}{*}{$1(\mathrm{~d})$} & 1. Obtained $y-4 x+4$ & 15 & 4.9 \\
\hline & 2. Failed to Attempt & 146 & 48.0 \\
\hline & 3. Obtained $y=x^{2}$ & 6 & 2.0 \\
\hline & 4. Obtained $y=x+4$ or $y=4 x$ & 52 & 17.1 \\
\hline & 5. Others & 85 & 28.0 \\
\hline \multirow{5}{*}{ 1(e) } & 1. Obtained 31 & 12 & 3.9 \\
\hline & 2. Failed to Attempt & 173 & 56.9 \\
\hline & 3. Obtained 512 or 132 or 124 & 10 & 3.3 \\
\hline & 4. obtained 32 & 47 & 15.5 \\
\hline & 5. Others & 62 & 20.4 \\
\hline
\end{tabular}

Table 4. Students' Working Processes on the Extended Abstract Level.

\begin{tabular}{|c|c|c|c|}
\hline Item & Working Processes & $n$ & $\%$ \\
\hline \multirow{5}{*}{$1(\mathrm{f})$} & $\begin{array}{l}\text { 1. Used Relations and } \\
\text { Mapping }\end{array}$ & 5 & 1.6 \\
\hline & 6. Failed to Attempt & 218 & 71.7 \\
\hline & $\begin{array}{l}\text { 7. Added } 2 \text { to unknown pool } \\
\text { number }(\mathrm{x})\end{array}$ & 20 & 6.6 \\
\hline & $(x)$ by 2 & 13 & 4.3 \\
\hline & 9. Other relations & 48 & 15.8 \\
\hline
\end{tabular}

\section{Discussions}

It was found that most students relied on the illustration in the question to answer the Uni-structural item (1a) (See Table 1) by counting the number of tiles required around the pool. This confirms the study by Lim, Wun and Idris (2005a) who stated that the low ability Malaysian students used pictorial representation to answer questions. Few students whose working processes could not be classified under any of the four themes was coded as Others and it shows that students were unfamiliar with the test items.

Most of the students at the Multi structural level recognized that as the number of the pool increased by one, the number of tiles required around it also increased by four (See Table 2). However, they failed to recognize a linkage between the algebraic concepts they have learnt in the JHS and the practical approach to the tilling pool problem. It could be deduced from the responses given by the students to item $1 \mathrm{~b}$ that the students were used to routine questions that requires standard algorithms and perhaps might not have the ability to address daily situations which usually exist outside the classroom environment.

The findings also showed that the students at the Relational level (See Table 3) were inconsistent with finding appropriate expression and relation or determining which of the variables they were 
supposed to substitute 128 tiles for. The number of students who used the correct working process to obtain the expression was greater than the number of students who used the correct working process to obtain the relation as well as the number of students who recognized that 128 tiles was the value of $y$ in the relation. This is in contrast with findings by Lim, Wun and Idris (2005a) that the high ability students (relational and extended abstract level) seemed to be more able to seek out the recurring linear pattern and identify the linear relationship between the variables. Lim, Wun and Idris (2005a) claimed that students could co-ordinate all the information given to generalize the pattern algebraically such as forming an algebraic expression and linear equation, used the linear pattern concept in more abstract situation such as forming a rule for the new linear pattern that they created. They also indicated that students used their methods more consistently to find solutions. This appear to contradict the finding in this study. This contradiction could stem from difference in sampling technique and sample size or perhaps variations in the teaching and learning practices at both study settings.

The analysis of the working processes of students in this study revealed that only five of the surveyed students could use the correct working processes to arrive at the correct relation in the Extended Abstract level item (See Table 4). This is a clear indication that there exists a wide gap between the algebraic concepts learned by Ghanaian students in class and the application of the concepts learned. This is seen by the huge increase of the number of students who failed to attempt subsequent question at the levels as the tiling pool problem increased in complexity from the concrete to the abstract. It is not surprising that Anamuah-Mensah, Mereku, and Ghartey-Ampiah (2008) stated that Ghanaian students who participated in the Trends in International Mathematics and Science Study in both 2003 and 2007 performed abysmally poor especially in higher order thinking test.

A wide range of research contends that algebraic thinking remains an integral part of mathematics responsible for students' competencies in problem solving and scientific discoveries. In this study, it is quite revealing to understand that majority of first year senior high students are not able to tackle questions at the relational level. This suggests that such students may not be achieving the mathematical knowledge needed to drive scientific advancement in Ghana as stated in the mathematics curriculum (Ministry of Education (MOE), 2012). Effort must therefore be taken to ensure students attain the algebraic competency stipulated in the mathematics curriculum.

\section{Recommendation}

From the findings, is it likely that JHS mathematics teachers who are responsible for preparing students for the SHS in Ghana do not pay attention to alternative assessment tools and the working processes of their students. If yes, it is recommended that teachers need to be innovative in their assessment techniques and be abreast of current trends of assessing mathematical knowledge and application. Teachers should also take interest in the working processes of their students as this will enable them to identify and plan appropriate interventions to address students' difficulties especially on non-routine tasks. JHS students should not only pay attention to solving routine problems but also be able to link the concepts learnt in class to non-routine problems and apply the same working process to solve mathematical tasks.

\section{Acknowledgements}

We are very grateful to the schools and the students who participated in this study. 


\section{References}

Anamuah-Mensah, J., Mereku, D. K., \& Ghartey-Ampiah, J. (2008). Ghanaian Junior Secondary School Students' Achievement in Mathematics and Science: Results from Ghana's participation in the 2007 Trends in International Mathematics and Science Study. Accra: Ministry of Education Youth and Sports.

Collis, K. F., Romberg, T. A. \& Jurdak, M. E. (1986). A Technique for Assessing Mathematical Problem-Solving Ability. Journal for Research in Mathematics Education, 17(3), 206-221.

Creswell, J. W. (2009). Research Design. Qualitative, Quantitative, and Mixed Methods Approaches. 3rd ed., Thousand Oaks: CA. Sage.

Fletcher, J. A. (2008). Developing Algebraic Thinking Through Group Discussion Mathematics Connection, 7(3), 25-34.

Kaput, J. (2008). What is Algebra? What is Algebraic reasoning? In J. J. Kaput, D. W. Carraher\& M. L. Blanton (Eds.), Algebra in the early grades (pp. 235-272). New York: Lawrence Erlbaum Associates.

Kriegler, S. (2008). Just What is Algebraic Thinking? http://www.math.ucla.edu/kriegler/pub/Algebrat.html (Accessed 2011)

Kvale, S., \& Brinkman, S. (2009). Interviews. Learning the Craft of Qualitative Research Interviewing. (2nd ed) London: SAGE Publication, Inc.

Lam, P., \& Fong, Y. Y. (1998). Assessment of Mathematics Structure of Learning Outcome Proficiency Attainment Level using Hierarchical items in Testlets. Educational Research Quarterly, 27(2), 3-15.

Lim, L. H., \& Idris, N. (2006). Assessing Algebraic Solving Ability of Form Four Students. International Electronic Journal of Mathematics Education, 1(1), 55-73.

Lim, L. H., Wun, Y. T., \& Idris, N. (2005a). Superitem Test: An Alternative Assessment Tool to Assess Students' Algebraic Solving Ability. School of Educational Studies. Universiti Sains Malaysia 11800 Minden, Pulau Pinang Malaysia.

Lim, L. H., Wun, Y. T., Idris, N., \& Meng, C. C. (2005b). Assessing a Hierarchy of Pre- Service Teachers' Algebraic Thinking of Equation. www.recsam.edu.my (September 2011)

Mereku, D. K., \& Cofie, P. K (2008). Overcoming Language Difficulties in Solving Mathematics Problems in Basic Schools in Ghana. Mathematics Connection, 7(7), 77-89.

Mereku, D. K. (2004). Mathematics Curriculum: Implementation In Ghana. Danjoe Production: Accra, Ghana.

Ministry of Education (MOE). (2012). Teaching Syllabus for Mathematics in Ghana. Accra,Ghana: Ministry of Education.

Owusu-Ansah N. A., Cofie P. O. \& Asiedu Adoo S. A. (2015). Classifying the Algebraic Thinking Levels of Ghanaian Junior High School Students in Mathematics using SOLO Taxonomy. Journal of Science Education and Research 1(5), 49-56.

UNICEF (2007). East Asia Learning Achievement Study. Keen Media, Thailand.

Wilson, M., \& Iventosh, L. (1988). Using the Partial Credit Model to Investigate Responses to Structured Subtest. Applied Measurement in Education, 1(4), 319-334.

Windsor, W. (2010). Shaping the Future of Mathematics Education: Proceedings of the 33rd annual conference of the Mathematics Education Research Group of Australasia. Fremantle: MERGA L. Sparrow, B. Kissane, \& C. Hurst (Eds.) 